\title{
Combinational PRR Agonists in Liposomal Adjuvant Enhances Immunogenicity and Protective Efficacy in a Tuberculosis Subunit Vaccine
}

Ling Hao, Yaqi Wu, Yandi Zhang, Zijie Zhou, Qing Lei, Nadeem Ullah, Jo-Lewis Banga Ndzouboukou, Xiaosong Lin and Xionglin Fan*

Department of Pathogen Biology, School of Basic Medicine, Tongji Medical College, Huazhong University of Science and Technology, Wuhan, China

OPEN ACCESS

Edited by:

Francesco Borriello,

Harvard Medical School, United States

Reviewed by:

Bernd Lepenies,

University of Veterinary Medicine

Hannover, Germany

Diana Quan-Le,

Centenary Institute, Australia

${ }^{*}$ Correspondence:

Xionglin Fan

xlfan@hust.edu.cn

Specialty section:

This article was submitted to Vaccines and Molecular Therapeutics, a section of the journal

Frontiers in Immunology

Received: 23 June 2020 Accepted: 15 September 2020 Published: 30 September 2020

Citation:

Hao L, Wu Y, Zhang Y, Zhou Z, Lei Q,

Ullah N, Banga Ndzouboukou J-L, Lin X and Fan X (2020) Combinational PRR Agonists in Liposomal Adjuvant Enhances Immunogenicity and Protective Efficacy in a

Tuberculosis Subunit Vaccine.

Front. Immunol. 11:575504. doi: 10.3389/fimmu.2020.575504
Bacillus Calmette-Guerin (BCG) is the only licensed vaccine to prevent children from tuberculosis (TB), whereas it cannot provide effective protection for adults. Our previous work showed a novel vaccine candidate, liposomal adjuvant DMT emulsified with a multistage antigen CMFO, could protect mice against primary progressive TB, latency, and reactivation. To develop a more effective vaccine against adult TB, we aimed to further understand the role of pattern recognition receptor (PRR) agonists monophosphoryl lipid A (MPLA) and trehalose-6,6'-dibehenate (TDB) of the liposomal adjuvant DMT in the CMFO subunit vaccine-induced protection. Using C57BL/6 mouse models, the current study prepared different dimethyldioctadecylammonium (DDA)-based liposomal adjuvants with MPLA, TDB, or both (DMT), and then compared the immunogenicity and the protective efficacy among different liposomal adjuvanted CMFO subunit vaccines. Our study demonstrated that CMFO/DMT provided stronger and longer-lasting protective efficacy than the CMFO emulsified with adjuvants DDA or DDATTDB. In addition, DDA MPLA adjuvanted CMFO conferred a comparable protection in the lung as CMFO/DMT did. Higher levels of IFN- $\gamma$, IL-2, TNF- $\alpha$, and IL-17A secreted by splenocytes were related with a more powerful and durable protection induced by CMFO/DMT through a putative synergistic effect of both MPLA and TDB via binding to TLR4 and Mincle. IL- $2^{+}$CD4 ${ }^{+} \mathrm{T}$ cells, especially $\mathrm{IL}-2^{+} \mathrm{CD} 4^{+} \mathrm{T}_{\mathrm{CM}}$ cells, in the lung after infection were significantly associated with the vaccine-induced protection, whereas stronger IL-10 response and lower $\mathrm{IL}-2^{+} \mathrm{CD}^{+} \mathrm{T}$ cells also contributed to the inferior protection of the DDATTDB adjuvanted CMFO subunit vaccine. Given their crucial roles in vaccine-induced protection, combinational different PRR agonists in adjuvant formulation represent a promising strategy for the development of next-generation TB vaccine.

Keywords: tuberculosis, subunit vaccine, Bacillus Calmette-Guerin, adjuvant, primary infection, patternrecognition receptor agonist, monophosphoryl lipid A, trehalose-6,6'-dibehenate 


\section{INTRODUCTION}

Despite the only licensed vaccine to prevent children from tuberculosis (TB), Bacillus Calmette-Guerin (BCG) vaccine cannot generate lifelong immunity, which has a limited protection period of no more than 15 years (1). Currently, adult is a major target population in pulmonary TB epidemics, which accounts for about $90 \%$ of the global TB burden (2). Moreover, about one-fourth of the world population has been estimated to be a status of latent TB infection (LTBI) and 5\%$10 \%$ of them would progress to active TB disease during lifetime (3). Such a situation is currently being exacerbated by the emergence of multidrug-resistant TB (MDR-TB) and extensively drug-resistant TB (XDR-TB), and co-infection with $\mathrm{HIV}$, respectively. As a major threat on global public health, a more effective vaccine is urgently needed to control adult TB.

Attempts have been made to develop novel TB vaccines, such as subunit vaccines, recombinant BCG vaccines, recombinant viral vectors, and attenuated strains, etc. (4). Among them, TB subunit vaccine has attracted increasing attention owing to its definite components and good safety. To produce a robust immune response to reduce the burden of Mycobacterium tuberculosis strains under various metabolic states in vivo, we and others constructed multistage subunit vaccines, such as A1D4 (Rv1813-Rv2660c-Ag85B-Rv2623-HspX) (5), WH121 (Rv3407-PhoY2-Ag85A-Rv2626c-RpfB) (6), CMFO (Rv2875Rv3044-Rv2073c-Rv0577) (7), ID93 (Rv3619-Rv1813-Rv3620Rv2608) (8), and H56 (Ag85B-ESAT-6-Rv2660c) (9), through combining antigens expressed by logarithmically growing and dormant $M$. tuberculosis strains. However, only the antigen CMFO emulsified with the novel liposome adjuvant DMT was validated to be an effective booster of the BCG vaccine $(7,10)$. Recent clinical trials showed that the efficacy of subunit vaccine candidates $\mathrm{M} 72 / \mathrm{ASO1}_{\mathrm{E}}$ (11) and H4:IC31 (12) to protect against adult TB was only $49.7 \%$ and $30.5 \%$, respectively. The imperfect efficacy of clinical trials spurs us on to greater efforts to understand the action mechanism of these candidates.

A significant proportion of adults have already received the BCG vaccination or have been latently infected with $M$. tuberculosis worldwide $(3,13)$. Under this context, cell-mediated immunity might be more required to play a critical role in the vaccine-induced protection. However, there is still a lack of effective adjuvants to induce appropriate cellular immune responses. The role of adjuvant as a decisive factor affecting the efficacy of TB subunit vaccine is often overlooked. The adjuvant DMT is formulated through the incorporation of dimethyldioctadecylammonium (DDA) liposome

\footnotetext{
Abbreviations: TB, tuberculosis; BCG, Bacillus Calmette-Guerin; DDA, dimethyldioctadecylammonium; MPLA, monophosphoryl lipid A; TDB, trehalose-6,6'-dibehenate; DM, DDA/MPLA; DT, DDA/TDB; DMT, DDA/ MPLA/TDB; LTBI, latent TB infection; MDR-TB, multidrug resistant TB; XDRTB, extensively drug resistant TB; A1D4, Rv1813-Rv2660c-Ag85B-Rv2623-HspX; WH121, Rv3407-PhoY2-Ag85A-Rv2626c-RpfB; CMFO, Rv2875-Rv3044Rv2073c-Rv0577; ID93, Rv3619-Rv1813-Rv3620-Rv2608; H56, Ag85B-ESAT-6Rv2660c; PRR, pattern-recognition receptor; TLR4, toll-like receptor 4; antigenpresenting cells, APCs; PDI, polydispersity index; s.c., subcutaneously; i.n., intranasally; CBA, cytometric bead array; FACS, fluorescence activated cell sorting; $\mathrm{T}_{\mathrm{CM}}$, central memory $\mathrm{T}$ cell; $\mathrm{T}_{\mathrm{EM}}$, effector memory $\mathrm{T}$ cell.
}

by toll-like receptor 4 (TLR4) and Mincle agonists, monophosphoryl lipid A (MPLA) and trehalose-6,6'-dibehenate (TDB) (14-16). The liposomal adjuvant $\mathrm{ASO1}_{\mathrm{E}}$ is composed of MPLA together with QS-21 (a triterpene saponin purified from Quillaja saponaria) (11). Another liposome-based adjuvant CAF01 also makes advantage of similar components such as DDA and TDB (17). The common component MPLA, a detoxified version of lipopolysaccharides, can be recognized by pattern recognition receptor (PRR) TLR4 expressing on the surface of antigenpresenting cells (APCs), which activates NF- $\mathrm{kB}$ through MyD88 and TRIF-dependent pathways and thus induces a Th1 biased response $(14,18-20)$. The other ingredient TDB, a synthetic analogue of mycobacterial cord factor, binds to the C-type lectin receptors Mincle and $\mathrm{Mcl}$ to activate macrophages (21) and could induce MyD88 and Card9-dependent Th1/Th17 responses in vivo against $M$. tuberculosis challenge $(22,23)$. In particular, these adjuvants and their ingredients have been demonstrated to be safe and tolerable in clinical trials $(11,17,24)$. We assumed that different PRR agonists might modulate the adjuvant effects of the liposomes and thus affect the efficacy of TB subunit vaccines. To develop a more effective vaccine against $\mathrm{TB}$, we aimed to further understand the role of both PRR agonists of the adjuvant DMT in vaccineinduced protection. In this study, we prepared different DDA-based liposomal adjuvants with MPLA, TDB, or both in this study, and then compared the immunogenicity and the protective efficacy among different liposomal adjuvanted $\mathrm{CMFO}$ subunit vaccines in C57BL/6 mouse models.

\section{MATERIALS AND METHODS}

\section{Preparation of Liposomal Adjuvants and Vaccines}

Four liposomal formulations (Table S1), namely, DDA, DDA/ MPLA (DM), DDA/TDB (DT), and DMT, were prepared using the lipid film hydration method as previously described (25). Briefly, weighed amounts of DDA (Avanti Polar Lipids Inc., AL, USA), MPLA (Avanti), or TDB (Avanti) were first dissolved in chloroform/methanol (9:1 in volume). The solvent was then blow-dried with $\mathrm{N}_{2}$ to form a thin lipid film by using a rotoevaporator. Samples were further dried under hypobaric condition overnight. Unilamellar vesicles were formed by hydrating the lipid film in sterile Tris-buffer $(10 \mathrm{mM}, \mathrm{pH} 7.4)$ at $60^{\circ} \mathrm{C}$ for $60 \mathrm{~min}$, followed by vortex every $10 \mathrm{~min}$. Recombinant CMFO protein was expressed by a genetically engineered expression system in $E$. coli and purified using nitrilotriacetic acidmetal ion affinity chromatography (GE Healthcare, NJ, USA) (7). The endotoxin in each purified products was removed $(<0.1 \mathrm{EU} / \mathrm{ml})$ by ToxinEraser $^{\mathrm{TM}}$ Endotoxin Removal Kit (Genscript, Nanjing, China). Different vaccines were prepared by mixing $100 \mu \mathrm{l}$ of CMFO solution $(0.2$ $\mathrm{mg} / \mathrm{ml}$ ) with $100 \mu \mathrm{l}$ liposomes (Table S1). Physicochemical property analysis of both liposomes and vaccine formulations were performed as our previously described (25). The results of the particle size, polydispersity index (PDI), and zeta potential from three batches of samples were presented as mean \pm SD. 


\section{Mice and Immunization}

Specific-pathogen-free female C57BL/6 mice, 6-8 weeks old, were obtained from the Charles River Company (Beijing, China) and maintained in animal feeding cabinet (VentiRack, CA, USA) in an ABSL-3 biosafety laboratory. Mice were randomly divided into different groups and immunized subcutaneously (s.c.) with different vaccine formulations (200 $\mu \mathrm{l} /$ dose) twice in a 3-week interval. PBS, different liposomal adjuvants DDA, DM, DT, and DMT alone were used as controls. Approximately, $1 \times 10^{6} \mathrm{CFU}$ of BCG China strain was vaccinated once as a positive control. All experiments were repeated twice.

\section{Challenge With Virulent $M$. tuberculosis H37Rv Strain}

To evaluate the short-term and long-term protective efficacy, mice vaccinated with different formulations were challenged intranasally (i.n.) with $\sim 100 \mathrm{CFU}$ of virulent $M$. tuberculosis $\mathrm{H} 37 \mathrm{Rv}$ strain at the $10^{\text {th }}$ and $20^{\text {th }}$ weeks. Four weeks post-challenge, the protective efficacy among different groups was assessed by comparing bacterial loads in both spleen and lung $(n=6)$, and by scoring the lung histopathological changes as previously described $(\mathrm{n}=3)$ (5). Briefly, bacterial load per organ was enumerated by plating $10-$ fold continuous dilutions of whole organ homogenates on $7 \mathrm{H} 11$ agar plates (Cat\#212203, BD Biosciences, NJ, USA). In addition, 2 $\mu \mathrm{g} / \mathrm{ml}$ of 2-thiophenecarboxylic acid hydrazide (Beijing Luqiao Corp, China) was selectively added to inhibit the residual BCG growth. The results were shown as $\log _{10}$ CFU/organ of individual animals $(n=6)$. The score was obtained by measuring the percentage of the consolidation area of the whole field of vision (magnification $\times 40$ ) and expressed as mean \pm SD of five fields of vision from each group $(n=3)$.

\section{Antibody Titer Determination of Antigen- Specific IgG and Its Subclasses}

Nine weeks after immunization, CMFO-specific endpoint titers for IgG, IgG1, and IgG2a (Cat\#151276, 133045, and 157720; Abcam, Cambridge, MA, USA) were detected in sera from each mouse by ELISA as previously described (7). The results were shown as $\log _{10}$ (endpoint titer) of individual animals $(n=6)$.

\section{Determination of Cytokines Secreted by Splenocytes}

Nine weeks after immunization or 4 weeks after infection, splenocytes from each mouse were aseptically seeded in triplicate in 24-well plates at the density of $5 \times 10^{6}$ cells/well. The cells were re-stimulated with $10 \mu \mathrm{g}$ CMFO for $72 \mathrm{~h}$. Culture supernatant was then collected and the cytokines secreted by splenocytes were detected using Mouse Th1 (IFN- $\gamma$, IL-2, and TNF- $\alpha$ ), Th2 (IL-4), Th17 (IL-17A), regulatory (IL-10 and IL-6) Cytokine Kit (BD Biosciences) based on cytometric bead array (CBA) technology (25).

\section{Detection of CMFO-Specific T Cells}

Nine weeks after immunization or four weeks after infection, intracellular flow cytometry was performed as previously described (7). Briefly, $5 \times 10^{6}$ splenocytes or lung cells from each mouse were seeded in triplicate in 24-well plates and incubated with CMFO $(10 \mu \mathrm{g})$ and anti-CD28/CD49d $(1 \mu \mathrm{g}$, eBioscience CA, USA) for $4 \mathrm{~h}$. Then, Brefeldin A (3 $\mu \mathrm{g})$ and monensin solution ( $2 \mu \mathrm{M}$, eBioscience) were added for further incubation for $12 \mathrm{~h}$. RPMI 1640 medium (Hyclone, USA) was used as a negative control. Cell stimulation cocktail $(1 \mu \mathrm{g}$, eBioscience) was used to monitor cell responses. Then, cells were collected and stained for $30 \mathrm{~min}$ at room temperature in the dark with surface markers, including anti-CD4-APC-Cy7 (Cat\#552051, BD Pharmingen ${ }^{\mathrm{TM}}$ ), anti-CD $8 \alpha-\mathrm{BV} 510$ (Cat\#563068, BD Horizon ${ }^{\mathrm{TM}}$ ), anti-CD44-FITC (Cat\#561859, BD Pharmingen ${ }^{\mathrm{TM}}$ ), and anti-CD62L-PerCP-Cy 5.5 (Cat\#560513, BD Pharmingen $^{\mathrm{TM}}$ ). After permeabilization using a Fixation/Permeabilization Solution Kit (Cat\#555028, BD Cytofix/Cytoperm ${ }^{\mathrm{TM}}$ Plus), cells were stained with intracellular markers, anti-IFN- $\gamma$-PE (Cat\#554412, BD Pharmingen ${ }^{\mathrm{TM}}$ ) and anti-IL-2-APC (Cat\#554429, BD Pharmingen ${ }^{\mathrm{TM}}$ ), for $30 \mathrm{~min}$ at room temperature in the dark. Stained cells $\left(5 \times 10^{5}\right)$ were collected and examined by an LSRII multicolor flow cytometry (BD Biosciences). FlowJo software (Tree Star Inc., OH, USA) was used to analyze the proportion of CMFO-specific IFN- $\gamma^{+}$(or $\left.\mathrm{IL}^{+} 2^{+}\right) \mathrm{T}$ cells, central memory $\mathrm{T}$ cells $\left(\mathrm{T}_{\mathrm{CM}}, \mathrm{CD} 62 \mathrm{~L}^{\mathrm{hi}} \mathrm{CD} 44^{\mathrm{hi}}\right)$, and effector memory $\mathrm{T}$ cells $\left(\mathrm{T}_{\mathrm{EM}}, \mathrm{CD} 62 \mathrm{~L}^{\mathrm{lo}} \mathrm{CD} 44^{\mathrm{hi}}\right)$ per organ. The absolute number of each $\mathrm{T}$ cell subpopulation was obtained by multiplying its proportion by the total number of the organ cells.

\section{Statistical Analyses}

Statistical analyses were performed using GraphPad Prism 5.0 (San Diego, CA, USA). Two-tailed student's $t$-test was used for two-group comparison. Multigroup analyses were carried out by one-way ANOVA test, and Tukey's multiple comparison test was used for further pair-wise comparison. A significant difference was considered when a $p$ value was less than 0.05 .

\section{RESULTS}

\section{Physicochemical Characteristics of Both Liposomes and CMFO-Liposome Complexes}

Different liposomes had a similar morphology and formed nearly spherical vesicles as our previous demonstrated by transmission electron microscopy (data not shown) (25). Compared with the DDA liposome, an addition of TDB and/or MPLA into the DDA liposome did not result in the change of particle size and PDI (Figure 1). In line with previous studies (25, 26), the incorporation of MPLA into DDA vesicles resulted in a significant decrease of the surface charge, as demonstrated by the lower Zeta potential values of DM and DMT. The antigen CMFO, emulsified with different liposomes, resulted in a general trend of increased particle size and PDI while reduced zeta potential across all four formulations. In particular, the particle sizes of $\mathrm{CMFO} / \mathrm{DM}, \mathrm{CMFO} / \mathrm{DT}$, and $\mathrm{CMFO} / \mathrm{DMT}$ were 


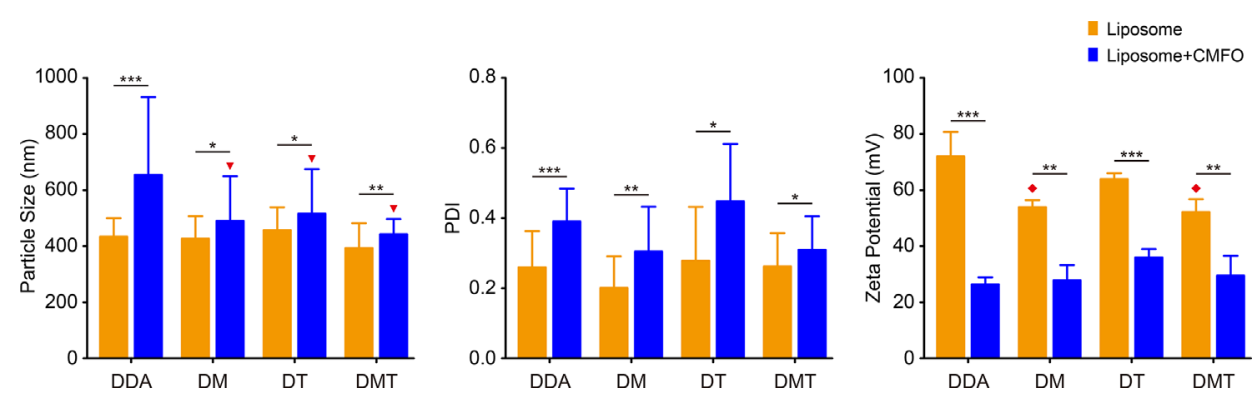

FIGURE 1 | The particle size, PDI, and zeta potential of both liposomes and CMFO-liposome complexes. Results were shown as mean \pm SD of three independent liposome batches. ${ }^{\star} p<0.05,{ }^{\star \star} p<0.01,{ }^{\star \star \star} p<0.001,{ }^{*} p<0.01$ vs. CMFO/DDA, and $p<0.05$ vs. DDA.

significantly smaller than that of CMFO/DDA, respectively. However, all CMFO-liposome complexes remained cationic.

\section{Short- and Long-Term Protection Among Liposomal Adjuvanted Subunit Vaccines}

To confirm the effect of different adjuvants on the short-term protective efficacy, C57BL/6 mice were vaccinated with different vaccines as described in Figure 2A and then challenged with $M$. tuberculosis at the 10th week after immunization. All of liposomal adjuvanted CMFO subunit vaccines resulted in a lower organ bacterial load than their respective adjuvant alone treated controls (Figures 2B, C). Notably, CMFO/DMT showed the strongest protection among liposomal adjuvanted CMFO subunit vaccines, as demonstrated by bacterial load in both lung and spleen, lung histopathological changes and scores (Figures 2B-E). Consistent with our previous findings (7), there was no statistical difference of bacterial loads in the lung or spleen between CMFO/DMT and $\mathrm{BCG}$ groups. Interestingly, when compared with the CMFO/DDA group, CMFO/DMT exhibited a stronger ability to inhibit the growth of M. tuberculosis in both lung and spleen, respectively. However, mice vaccinated with CMFO/DMT only had a lower bacterial load in their spleen than $\mathrm{CMFO} / \mathrm{DM}$ or CMFO/DT did (Figure 2C).

At the $20^{\text {th }}$ week, vaccinated mice were further challenged with $M$. tuberculosis to examine long-term protective efficacy (Figure 3A). Of the all groups, PBS control group still had the highest organ bacterial loads and lung pathological scores. Surprisingly, mice vaccinated with CMFO/DMT had more significantly decreased bacterial load than did with DDA or DT adjuvanted CMFO vaccines (Figures 3B, C). In comparison with the CMFO/DM vaccine, CMFO/DMT had milder lung histopathological change and lower score (Figures 3D, E). However, both groups had no statistical difference in terms of bacterial load in lung and spleen (Figures 3B, C).

\section{Similar Patterns of Antibody Response Elicited by Liposomal Adjuvanted Subunit Vaccines}

To analyze the effect of different adjuvants on antibody production, CMFO-specific antibodies, including IgG, IgG2a, and IgG1, in the sera of different vaccinated mice were tested by ELISA. As expected, PBS and adjuvant control groups did not produce any antigen-specific antibodies (data not shown). When compared with the CMFO/DDA group, CMFO/DMT induced much higher levels of CMFO-specific IgG, IgG2a, and IgG1, while CMFO/DM elicited stronger anti-CMFO IgG and IgG2a responses (Figures $\mathbf{4 A - C}$ ). Interestingly, four liposome-based CMFO subunit vaccinated groups induced similar antibody responses, as evidenced by the ratio of IgG2a/IgG1 response to CMFO (Figure 4D).

\section{Differential Cytokine Profiles Among Liposomal Adjuvanted Subunit Vaccines}

CMFO-specific cytokine profiles in the supernatant of splenocytes from different vaccination groups before and after challenge were detected by using a CBA kit. Prior to the exposure, splenocytes from BCG vaccinated mice secreted the higher levels of CMFO-specific IFN- $\gamma$, IL-2, IL-6, IL-17A, and TNF- $\alpha$ than those from the PBS control group (Figure 5). When compared with DDA alone, DMT alone significantly increased the levels of CMFO-specific IFN- $\gamma$, IL-6, IL-17A, or TNF- $\alpha$, while DM alone enhanced the secretion of IFN- $\gamma$, IL- 6 , and TNF- $\alpha$. Different liposomal adjuvanted CMFO vaccinated mice elicited higher levels of IFN- $\gamma$, IL-2, IL-6, IL-17A, and TNF$\alpha$ than their respective adjuvant alone controls. In particular, CMFO/DMT induced the highest levels of IFN- $\gamma$, IL-2, IL-17A, and TNF- $\alpha$ of all groups. In addition, mice vaccinated with either $\mathrm{CMFO} / \mathrm{DM}$ or CMFO/DT also produced more IFN- $\gamma$, IL-2, IL-6, TNF- $\alpha$, and IL-17A than CMFO/DDA did. Only IL-2 response to $\mathrm{CMFO}$ in the $\mathrm{CMFO} / \mathrm{DM}$ group was stronger than that in the CMFO/DT group (Figure 5B), while splenocytes from the CMFO/DT vaccinated mice secreted more CMFO-specific IL-6, IL-10, and IL17A than those of the CMFO/DM vaccinated mice (Figures 5C-E). Interestingly, CMFO/DT induced the highest level of IL-10 among all liposomal adjvanted CMFO vaccinated mice (Figure 5D).

After exposure, the levels of CMFO-specific IL-10 and IL-17A were decreased significantly, whereas IL-2 secretion from splenocytes of different groups had a marked increase (Figure 6). Mainly, the results of different groups post-exposure were 

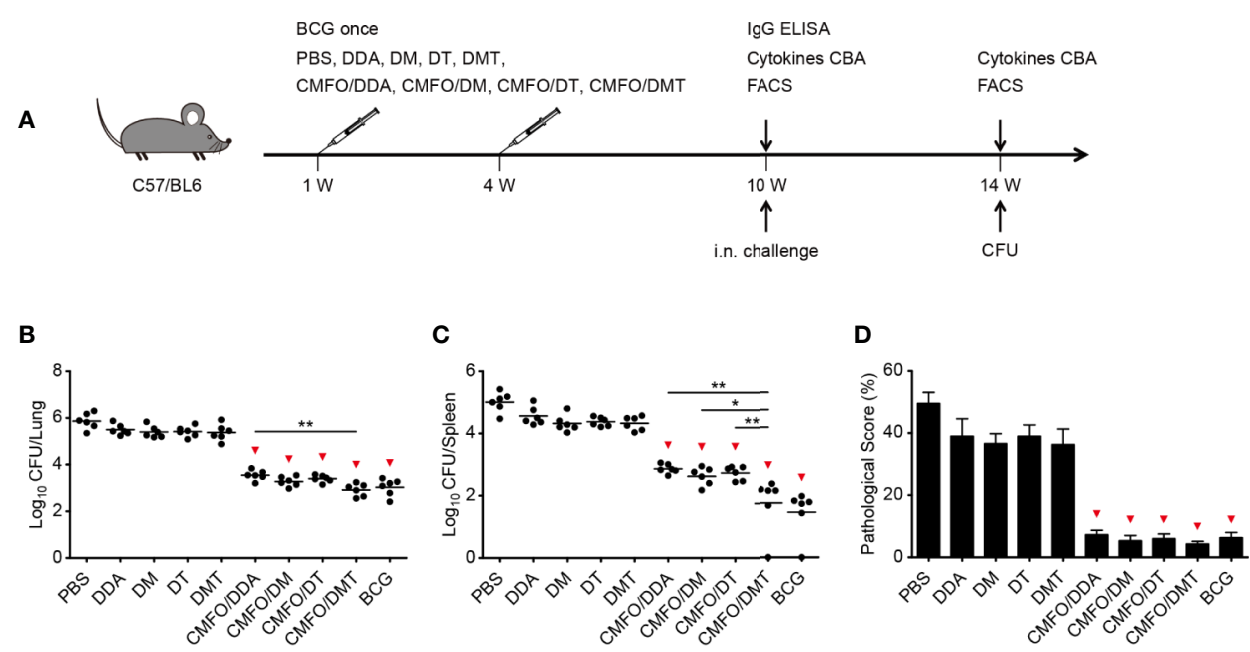

E

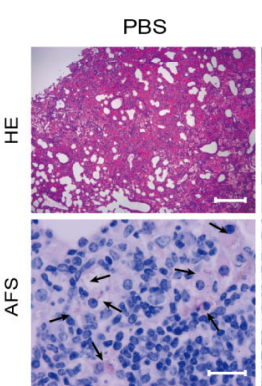

DDA

DM

DT
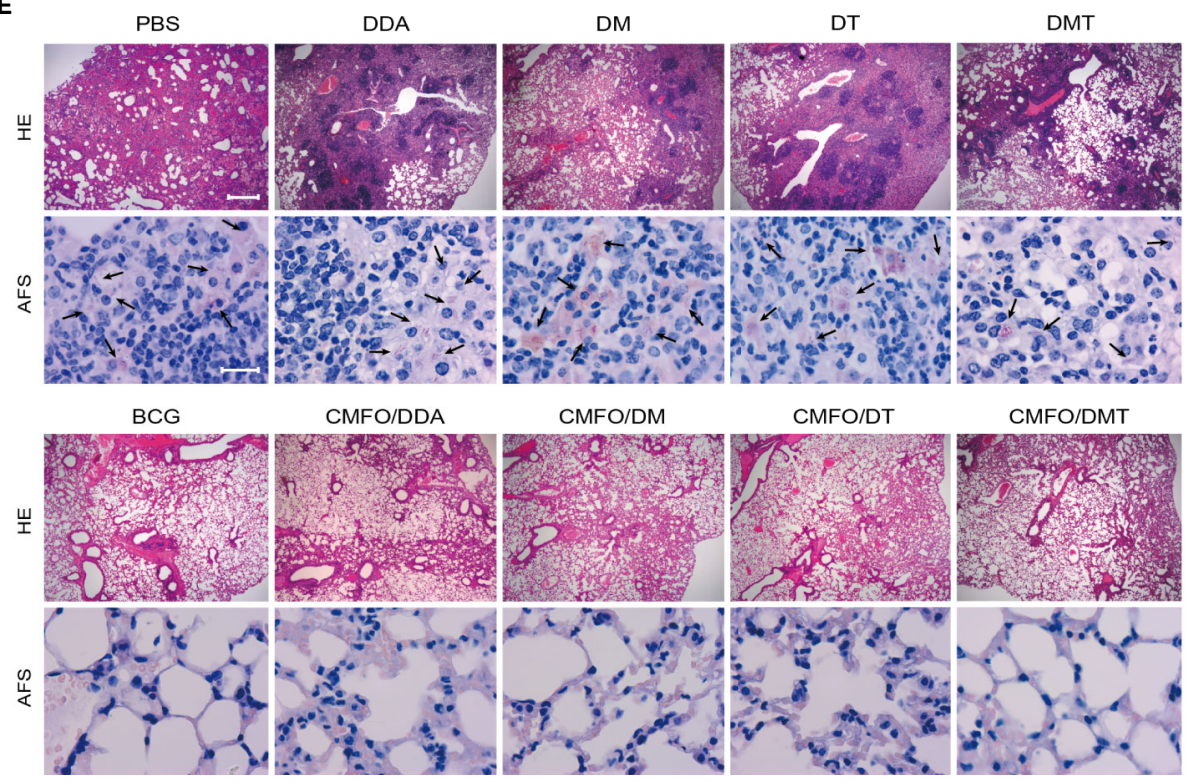

CMFO/DM

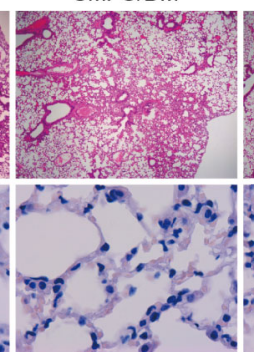

CMFO/DT

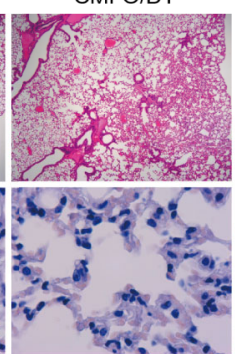

CMFO/DMT

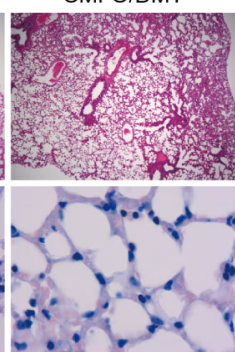

FIGURE 2 | Comparison of the short-term protective efficacy against primary TB infection among different regimens. (A) Vaccination and challenge schedule. At the $14^{\text {th }}$ week, bacterial load in the lung $(\mathbf{B})$ and the spleen $\mathbf{( C )}$ of different groups was enumerated and shown as Log ${ }_{10}$ CFU/organ of individual animals $(n=6)$. The line in each group represented mean value. (D) The lung pathological scores of different groups. ${ }^{*} p<0.05$, ${ }^{* *} p<0.01$, and ${ }^{\mathbf{}} p<0.05$ vs. respective controls. (E) The representative lung pathological changes were shown for HE and AF staining $(n=3)$. HE, hematoxylin-eosin; AFS, acid-fast staining. Scar bar: $400 \mu m$ for $\mathrm{HE}$ staining, $20 \mu \mathrm{m}$ for AF staining. Arrows indicated AF-positive bacteria. All experiments were repeated twice and similar results were obtained.

consistent with those pre-exposure, in addition to the splenocytes from the CMFO/DT vaccinated mice secreted more CMFO-specific IFN- $\gamma$, IL-6, IL-10, and IL-17A than those of the CMFO/DM vaccinated mice. Whatever before and after exposure, the level of IL-4 in all groups was very low, less than $1 \mathrm{pg} / \mathrm{ml}$ (data not shown).

\section{Differential T Cell Responses Induced in Spleens Before and After Infection}

To investigate immunological effects related with the protection against primary infection, the numbers of CMFO-specific IFN- $\gamma^{+}$(or IL-2 ${ }^{+}$) T cells, IL-2 ${ }^{+} \mathrm{T}_{\mathrm{CM}}\left(\mathrm{CD} 62 \mathrm{~L}^{\mathrm{hi}} \mathrm{CD} 44^{\mathrm{hi}}\right)$ cells, and IFN- $\gamma^{+} \mathrm{T}_{\mathrm{EM}}\left(\mathrm{CD} 62 \mathrm{~L}^{\mathrm{lo}} \mathrm{CD} 44^{\mathrm{hi}}\right)$ cells in splenocytes from different vaccinated mice were determined by fluorescence activated cell sorting (FACS) before (Figures 7A, B) and after infection (Figure 8). CMFO-specific IFN- $\gamma^{+} \mathrm{CD} 4^{+} \mathrm{T}$ cells and IFN- $\gamma^{+} \mathrm{CD}^{+} \mathrm{T}_{\mathrm{EM}}$ cells were dominated in the spleen of all vaccinated mice before the exposure (Figure $7 \mathbf{B}$ ). As expected, the BCG group had higher numbers of CMFO-specific T cells than that from the PBS control. Liposomal adjuvants alone did not induce any of these $\mathrm{T}$ cells at the $10^{\text {th }}$ week. Interestingly, CMFO/DMT induced the highest levels of IFN $-\gamma^{+}$or IL-2 ${ }^{+}$ 

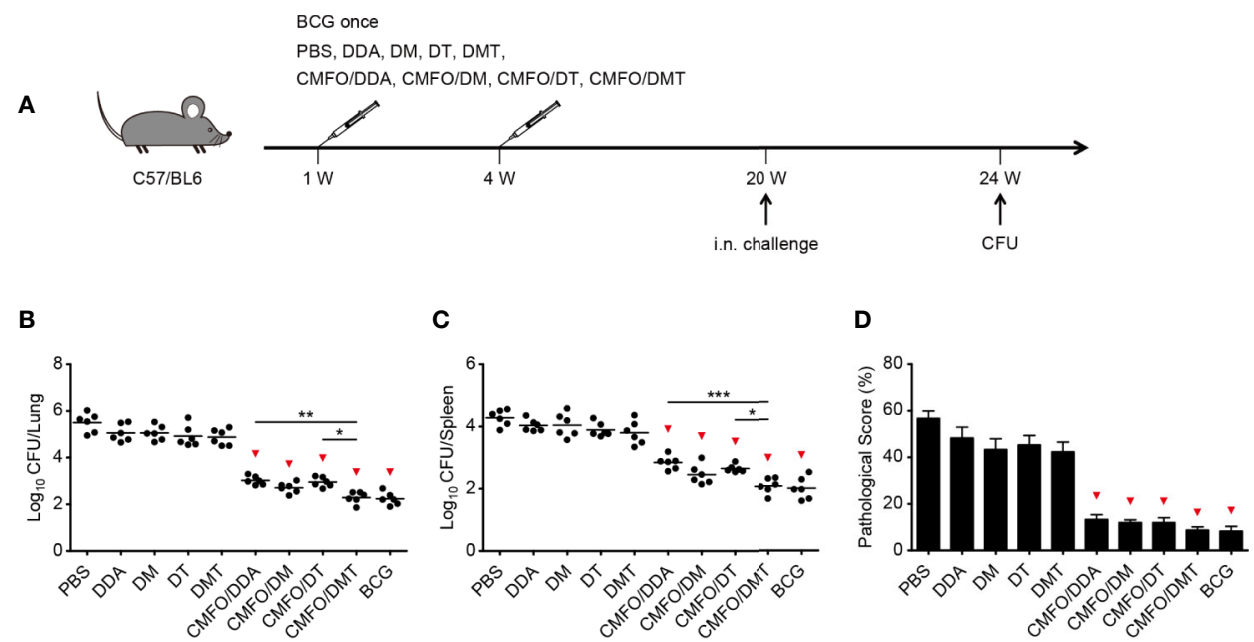

E
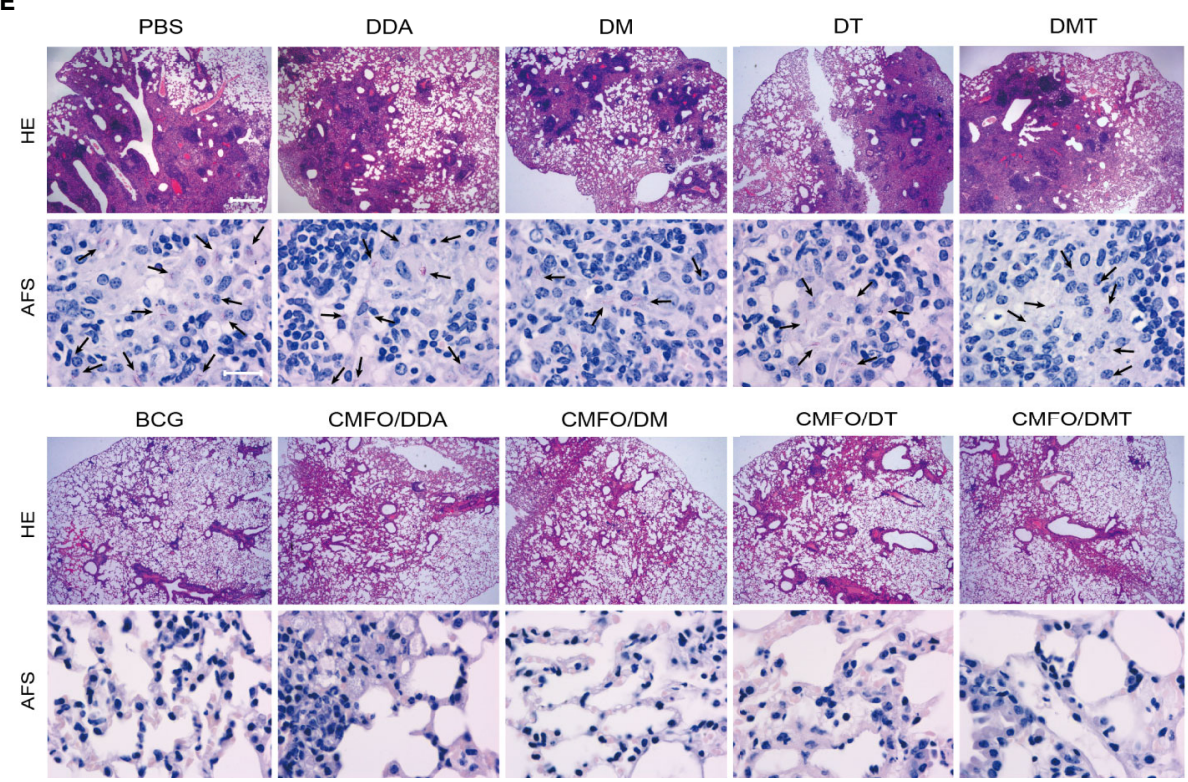

FIGURE 3 | Comparison of the long-term protective efficacy against primary TB infection among different regimens. (A) Vaccination and challenge schedule. At the $24^{\text {th }}$ week, bacterial load in the lung (B) and the spleen (C) of different groups was enumerated and shown as Log ${ }_{10}$ CFU/organ of individual animals $(n=6)$. The line in each group represented mean value. (D) The lung pathological scores of different groups. ${ }^{*} p<0.05,{ }^{* *} p<0.01,{ }^{* * *} p<0.001$, and ${ }^{\star} p<0.05$ vs. respective controls. (E) The representative lung pathological changes were shown for HE and AF staining $(n=3)$. HE, hematoxylin-eosin; AFS, acid-fast staining. Scar bar: 400 $\mu \mathrm{m}$ for $\mathrm{HE}$ staining, $20 \mu \mathrm{m}$ for AF staining. Arrows indicated AF-positive bacteria. All experiments were repeated twice and similar results were obtained.

$\mathrm{CD}^{+} \mathrm{T}$ cells, IFN- $\gamma^{+} \mathrm{CD} 4^{+} \mathrm{T}_{\mathrm{EM}}$ cells, and IL-2 ${ }^{+} \mathrm{CD} 4^{+} \mathrm{T}_{\mathrm{CM}}$ cells in the spleen of all groups. When compared with the CMFO/DDA group, CMFO/DM induced more $\mathrm{IL}-2^{+} \mathrm{CD} 4^{+} \mathrm{T}$ cells and IL-2 ${ }^{+} \mathrm{T}_{\mathrm{CM}}$ cells, while CMFO/DT induced more IFN$\gamma^{+}$or IL-2 ${ }^{+} \mathrm{CD}^{+} \mathrm{T}$ cells and IFN- $\gamma^{+} \mathrm{CD} 4^{+} \mathrm{T}_{\mathrm{EM}}$ cells. More importantly, both DM and DMT adjuvanted CMFO vaccines elicited more $\mathrm{IL}-2^{+} \mathrm{CD} 8^{+} \mathrm{T}_{\mathrm{CM}}$ cells than $\mathrm{CMFO} / \mathrm{DDA}$ or $\mathrm{CMFO} / \mathrm{DT}$ did.

After infection, $\mathrm{IL}_{-} 2^{+} \mathrm{CD} 4^{+} \mathrm{T}$ cells and $\mathrm{T}_{\mathrm{CM}}$ cells were dominant in the spleen of all groups (Figure 8). Among all groups, $\mathrm{CMFO} / \mathrm{DMT}$ induced the highest levels of CMFO- specific IFN- $\gamma^{+} \mathrm{T}$ cells, IFN- $\gamma^{+} \mathrm{CD} 4^{+} \mathrm{T}_{\mathrm{EM}}$ cells, and IL-2 ${ }^{+}$ $\mathrm{CD}^{+} \mathrm{T}$ cells or $\mathrm{T}_{\mathrm{CM}}$ cells. When compared with the $\mathrm{CMFO} /$ DDA group, CMFO/DM induced more IFN $-\gamma^{+} \mathrm{CD} 4^{+} \mathrm{T}_{\mathrm{EM}}$ cells, IL-2 ${ }^{+} \mathrm{CD} 4^{+} \mathrm{T}$ cells, and IL-2 ${ }^{+} \mathrm{CD} 4^{+} \mathrm{T}_{\mathrm{CM}}$ cells, while CMFO/DT induced more IFN- $\gamma^{+} \mathrm{T}$ cells, IFN- $\gamma^{+} \mathrm{CD} 4^{+} \mathrm{T}_{\mathrm{EM}}$ cells, IL-2 ${ }^{+}$ $\mathrm{CD}^{+} \mathrm{T}$ cells, and IL-2 ${ }^{+} \mathrm{T}_{\mathrm{CM}}$ cells.

\section{Differential T Cell Responses Elicited in Lungs After Infection}

$\mathrm{T}$ cell responses to the antigen $\mathrm{CMFO}$ were also detected in the lung by FACS (Figures 9, 10). At the $10^{\text {th }}$ week after 

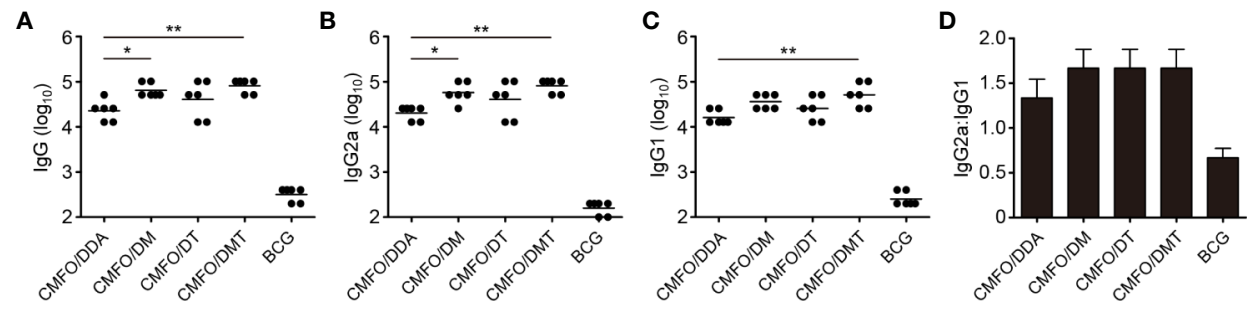

FIGURE 4 | Sera antigen-specific antibody responses $(n=6)$. Nine weeks after immunization, CMFO-specific endpoint titers for lgG (A), IgG2a (B), and IgG1 (C) in sera of mice were detected by ELISA. All results were shown as $\log _{10}$ endpoint titer of individual animals and the line in each group represented mean value. ${ }^{\star} p<$ 0.05 and ${ }^{* *} p<0.01$. (D) The ratio of lgG2a/lgG1 in different vaccinated mice. All experiments were repeated twice and similar results were obtained.
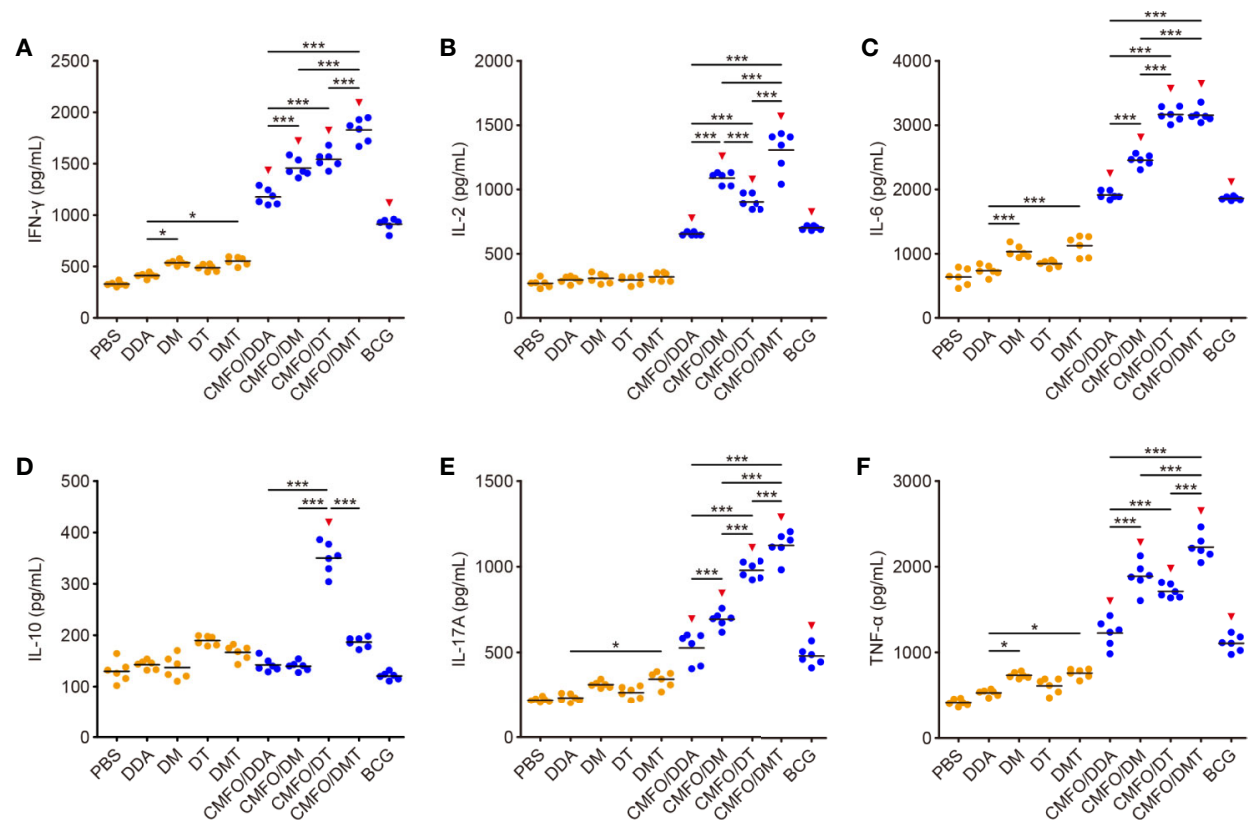

FIGURE 5 | CMFO-specific cytokine responses before exposure $(n=6)$. Nine weeks after immunization, CMFO-specific Th1/Th2/Th17 cytokines including IFN- $\gamma(\mathbf{A})$, IL-2 (B), IL-6 (C), IL-10 (D), IL-17 (E), and TNF- $\alpha$ (F) in the supernatant of splenocytes from different vaccinated mice were detected by a CBA kit. All experiments were repeated twice and similar results were obtained. The line in each group represented mean value. ${ }^{\star} p<0.05,{ }^{\star \star} p<0.001$, and ${ }^{\nabla} p<0.05$ vs. respective controls.

immunization, IL-2 ${ }^{+} \mathrm{CD} 4^{+} \mathrm{T}$ cells were dominated in all vaccinated mice (Figure 9). Different adjuvanted CMFO vaccines elicited higher levels of $\mathrm{IL}-2^{+} \mathrm{CD}^{+} \mathrm{T}$ cells than their respective adjuvant controls. However, the levels of CMFO-specific IFN- $\gamma^{+} \mathrm{T}$ cells or $\mathrm{T}_{\mathrm{EM}}$ cells, IL-2 ${ }^{+} \mathrm{CD} 8^{+} \mathrm{T}$ cells and IL-2 ${ }^{+} \mathrm{T}_{\mathrm{CM}}$ cells in the lung of all groups were very low, only less than $10^{4}$.

After infection, IL-2 ${ }^{+} \mathrm{CD}^{+} \mathrm{T}$ cells or $\mathrm{T}_{\mathrm{CM}}$ cells were still dominated in the lung of all vaccinated groups (Figure 10). Notably, CMFO/DMT elicited the highest levels of IFN- $\gamma^{+}$ or IL- $2^{+} \mathrm{CD}^{+} \mathrm{T}$ cells, IFN- $\gamma^{+} \mathrm{T}_{\mathrm{EM}}$ cells, and IL-2 ${ }^{+} \mathrm{CD} 4^{+} \mathrm{T}_{\mathrm{CM}}$ cells in the lung of all groups. When compared with the CMFO/ DDA group, CMFO/DM induced more IFN $-\gamma^{+}$or IL- $2^{+} \mathrm{T}$ cells,
IFN- $\gamma^{+} \mathrm{CD} 4^{+} \mathrm{T}_{\mathrm{EM}}$ cells, and IL- ${ }^{+} \mathrm{T}_{\mathrm{CM}}$ cells, while CMFO/DT induced more IFN- $\gamma^{+}$or IL- $2^{+} \mathrm{CD} 8^{+} \mathrm{T}$ cells, IFN- $\gamma^{+} \mathrm{CD} 4^{+} \mathrm{T}_{\mathrm{EM}}$ cells, and IL-2 ${ }^{+} \mathrm{T}_{\mathrm{CM}}$ cells. In addition, the similar levels of IFN- $\gamma^{+}$ or $\mathrm{IL}_{-} 2^{+} \mathrm{CD}^{+} \mathrm{T}$ cells were observed in DM, DT, and DMT adjuvanted $\mathrm{CMFO}$ vaccinated groups.

\section{DISCUSSION}

Currently, only a few subunit vaccine candidates with or without prime-boost strategies could exert superior effects than the BCG vaccine does against adult TB in preclinical or clinical trials $(27,28)$. To develop more effective vaccines, it is 

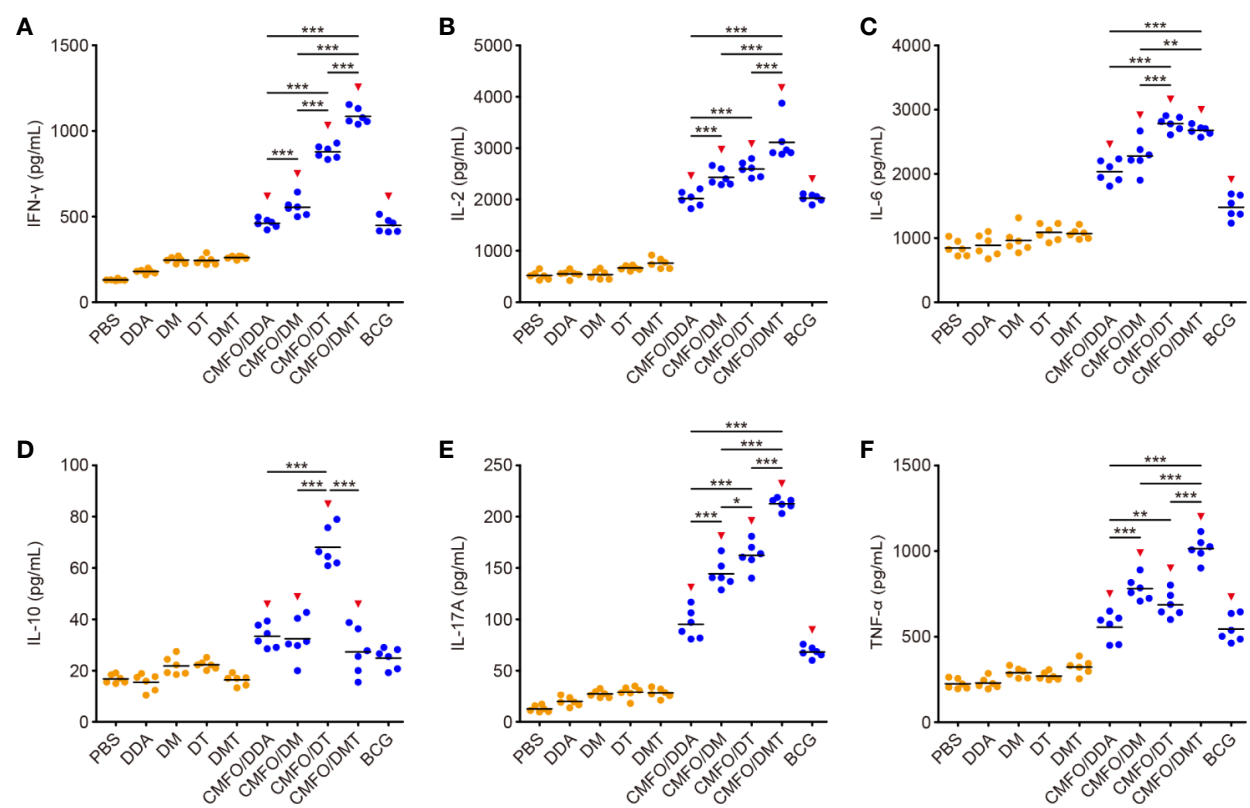

FIGURE 6 | CMFO-specific cytokine responses after exposure $(n=6)$. Nine weeks after immunization, C57BL/6 mice were challenged with $M$. tuberculosis. Four weeks after infection, CMFO-specific Th1/Th2/Th17 cytokines including IFN- $\gamma$ (A), IL-2 (B), IL-6 (C), IL-10 (D), IL-17 (E), and TNF- $\alpha$ (F) in the supernatant of splenocytes from different vaccinated mice were detected by a CBA kit. All experiments were repeated twice and similar results were obtained. The line in each group represented mean value. ${ }^{*} p<0.05,{ }^{* *} p<0.01,{ }^{* \star} p<0.001$, and ${ }^{\star} p<0.05$ vs. respective controls.

significant to understand the role of adjuvants on the efficacy of subunit vaccines. In this study, we investigated the effects of each components of the adjuvant DMT on the protection against primary $\mathrm{TB}$ infection in CMFO/DMT subunit vaccinated mice. Our study demonstrated a comparable efficiency between CMFO/DMT and BCG vaccines in terms of their short- and long-term protection. CMFO/DMT achieved a stronger and longer-lasting protection than that from CMFO emulsified with adjuvants DDA or DDA/TDB. Interestingly, DDA/MPLA adjuvanted CMFO could confer to a similar protection in the lung as did with CMFO/DMT. Adjuvants DDA/MPLA, DDA/TDB, and DMT induce similar antibody responses and all are strong inducers of Th1/Th17 cytokine responses. Compared with DMT and DDA/MPLA, the induction of strong IL-10 response and low $\mathrm{IL}-2^{+} \mathrm{CD} 4^{+} \mathrm{T}$ cells was relevant to the reduced protection of DDA/TDB adjuvanted CMFO subunit vaccine. Therefore, our findings confirmed that different PRR agonists could modulate the immune responses, especially cellular immune responses in subunit vaccinated mice. The DMT might be a very promising adjuvant for TB subunit vaccines.

Differential protective efficacy among liposomal adjuvanted CMFO subunit vaccines provides us opportunities to elucidate immunological mechanisms of different subcomponents in liposomal adjuvants. In this study, the introduction of the negatively charged MPLA into the DDA liposome significantly decreased the surface charge of the liposome, which might improve the stability of DDA-based liposomes as demonstrated in previous studies $(25,26)$. Cationic adjuvant systems, such as IC31 and CAF01, have been proved to be crucial for the formation of an antigen depot at the site-ofinjection, the prolonged uptake of antigens by APCs, and the ability of a vaccine to induce adaptive immune responses (2931). Our previous study also confirmed that the cationic adjuvant DMT had a slower and longer-lasting release effect on antigens and agonists than the DDA liposome (25). The recombinant antigen $\mathrm{CMFO}$ was negative charge, which could be readily adsorbed by the positively charged DMT liposome. The controlled release effect of the DMT adjuvant on antigens and agonists might result in the long-term deposition of the vaccine antigen at the injection site for APCs uptaking, increase the time of vaccine exposure to the immune cells, and thus facilitate the sustained Th1 responses. In the current study, both DM and DMT adjuvanted CMFO subunit vaccines potentiated the production of serum IgG and IgG2b antibodies than the antigen complexed with DDA alone, indicating that antibody-mediated immunity might also play roles in the protection against $\mathrm{TB}$, as previously reported (32-35). The multifaceted functions of the antibody have been proposed as mediating opsonic killing, removing immunomodulatory antigens of $M$. tuberculosis and modulating inflammation (36). Low-antibody titers and defective humoral immunity may increase the risk of $M$. tuberculosis infection and dissemination (37-39). More importantly, different liposomal adjuvanted CMFO vaccines also elicited differential cytokine profiles and $\mathrm{T}$ cell responses in the spleen and lung before and 


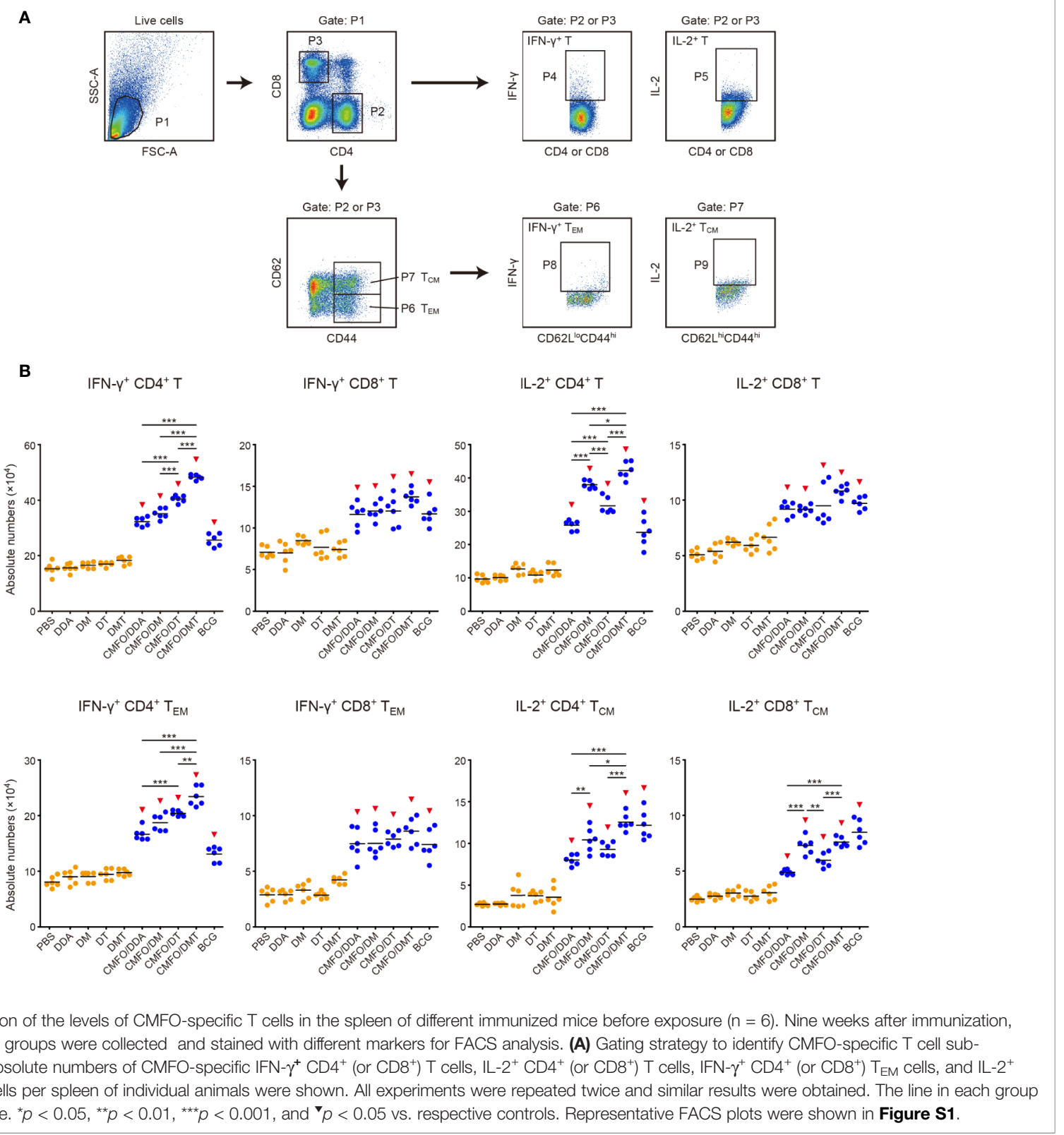

after exposure. In line with previous reports $(9,22,23,40)$, the adjuvant DDA/MPLA is a strong inducer of antigen-specific IFN- $\gamma$ and IL- 2 responses, while the adjuvant DDA/TDB stimulated high levels of antigen-specific IFN- $\gamma$ and IL-17A. However, DDA/TDB also induced the highest level of IL-10 responses to the antigen CMFO before and after infection of all groups. IL-10 suppresses the functions of macrophages and dendritic cells $(41,42)$, and thus might play a suppressive role in the efficacy of DDA/TDB emulsified CMFO subunit vaccine. Among all groups, DMT adjuvanted CMFO elicited the highest levels of IFN- $\gamma$, IL-2, TNF- $\alpha$, and IL-17A. IFN- $\gamma$ can trigger the activation of alveolar macrophage, thus killing engulfed $M$. tuberculosis (43-45). TNF- $\alpha$ triggers cytotoxic T cells to directly kill intracellular pathogen, and recruits monocytes and circulate antigen-specific $\mathrm{T}$ lymphocytes to the infection site $(46,47)$. IL-2 is secreted by activated T cells, which can promote the differentiation and proliferation of lymphoid cells, further enhancing the cell-mediated anti-infective immune responses (48). IL-17A plays a critical role in the formation of mature granuloma for pathogen containment at early disease stage (49-51). In addition, IL-6 could induce early IFN- $\gamma$ expression to inhibit $M$. tuberculosis growth, however it is not necessary for the development of protective immunity (52). Therefore, the CMFO/DMT induced protection correlates with the levels of IFN- $\gamma$, IL-2, TNF- $\alpha$, and IL-17A secreted by splenocytes, which might be a synergistic effect of 

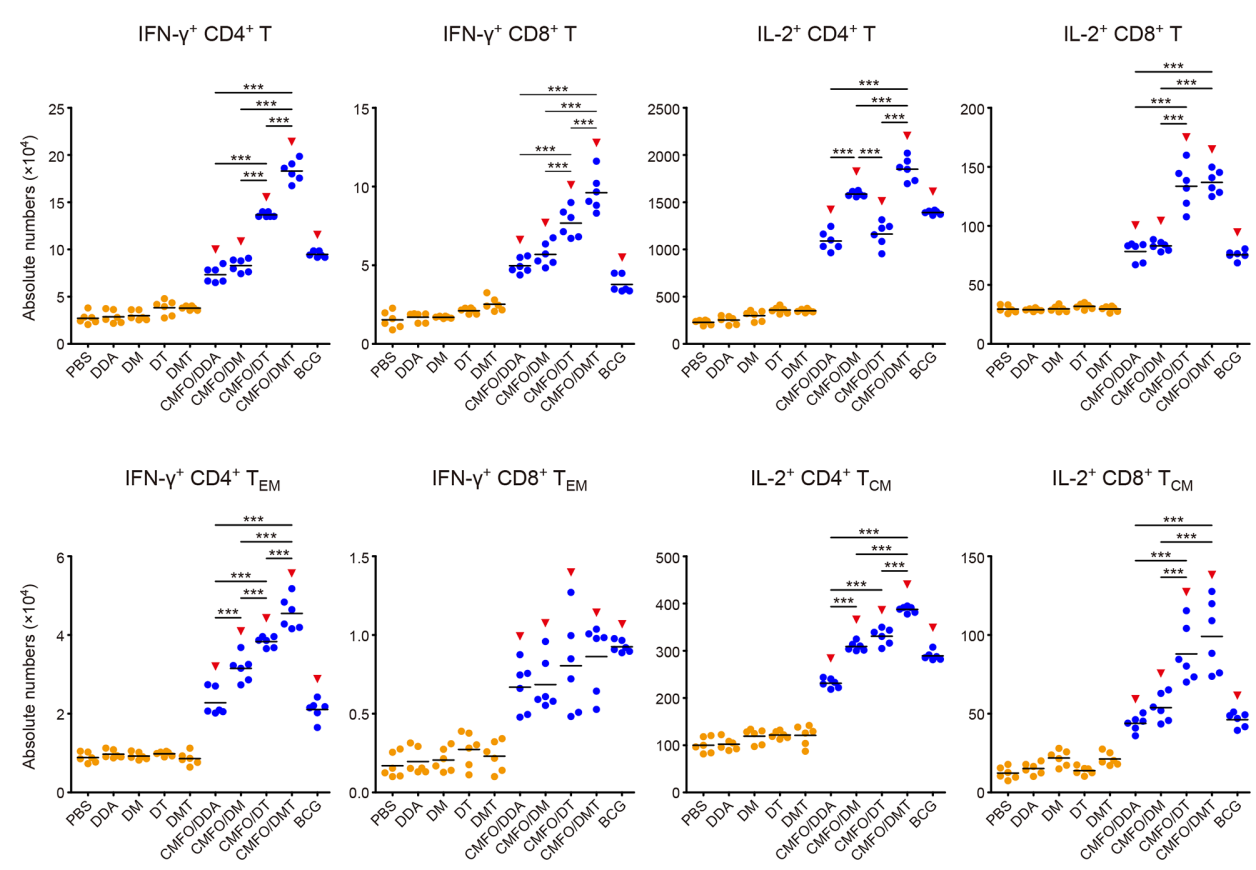

FIGURE 8 | Comparison of the levels of CMFO-specific T cells in the spleen of different immunized mice after exposure $(\mathrm{n}=6)$. Nine weeks after immunization, C57BL/6 mice were challenged with $M$. tuberculosis. Four weeks after infection, the absolute numbers of CMFO-specific IFN- $\gamma^{+} \mathrm{CD}_{4}^{+}\left(\right.$or $\left.\mathrm{CD} 8^{+}\right)$T cells, IFN- $\gamma^{+} \mathrm{CD} 4^{+}$ (or $\mathrm{CD} 8^{+}$) $\mathrm{T}_{\mathrm{EM}}$ cells, IL-2 $2^{+} \mathrm{CD} 4^{+}$(or CD8 $\left.{ }^{+}\right) \mathrm{T}$ cells, and IL-2 $\mathrm{CD}^{+}$(or CD8 ${ }^{+}$) $\mathrm{T}_{\mathrm{CM}}$ cells per spleen were detected. The experiments were repeated twice and similar results were obtained. The line in each group represented mean value. ${ }^{\star \star \star} p<0.001$ and ${ }^{*} p<0.05$ vs. respective controls. Representative FACS plots were shown in Figure S2.

IFN-Y $\mathrm{Y}^{+} \mathrm{CD} 4^{+} \mathrm{T}$

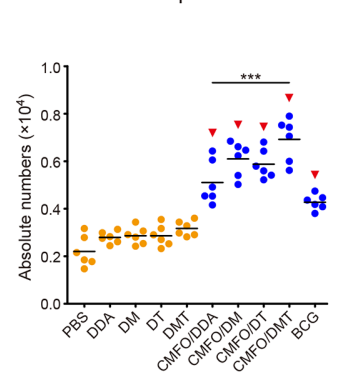

IFN- $\mathrm{r}^{+} \mathrm{CD} 4^{+} \mathrm{T}_{\mathrm{EM}}$

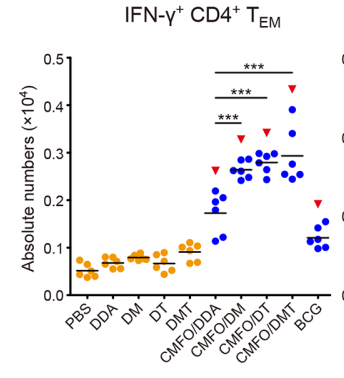

IFN- $-\mathrm{Y}^{+} \mathrm{CD} 8^{+} \mathrm{T}$

IL-2 ${ }^{+} \mathrm{CD} 4^{+} \mathrm{T}$
$\mathrm{IL}-2^{+} \mathrm{CD}^{+} \mathrm{T}$ 


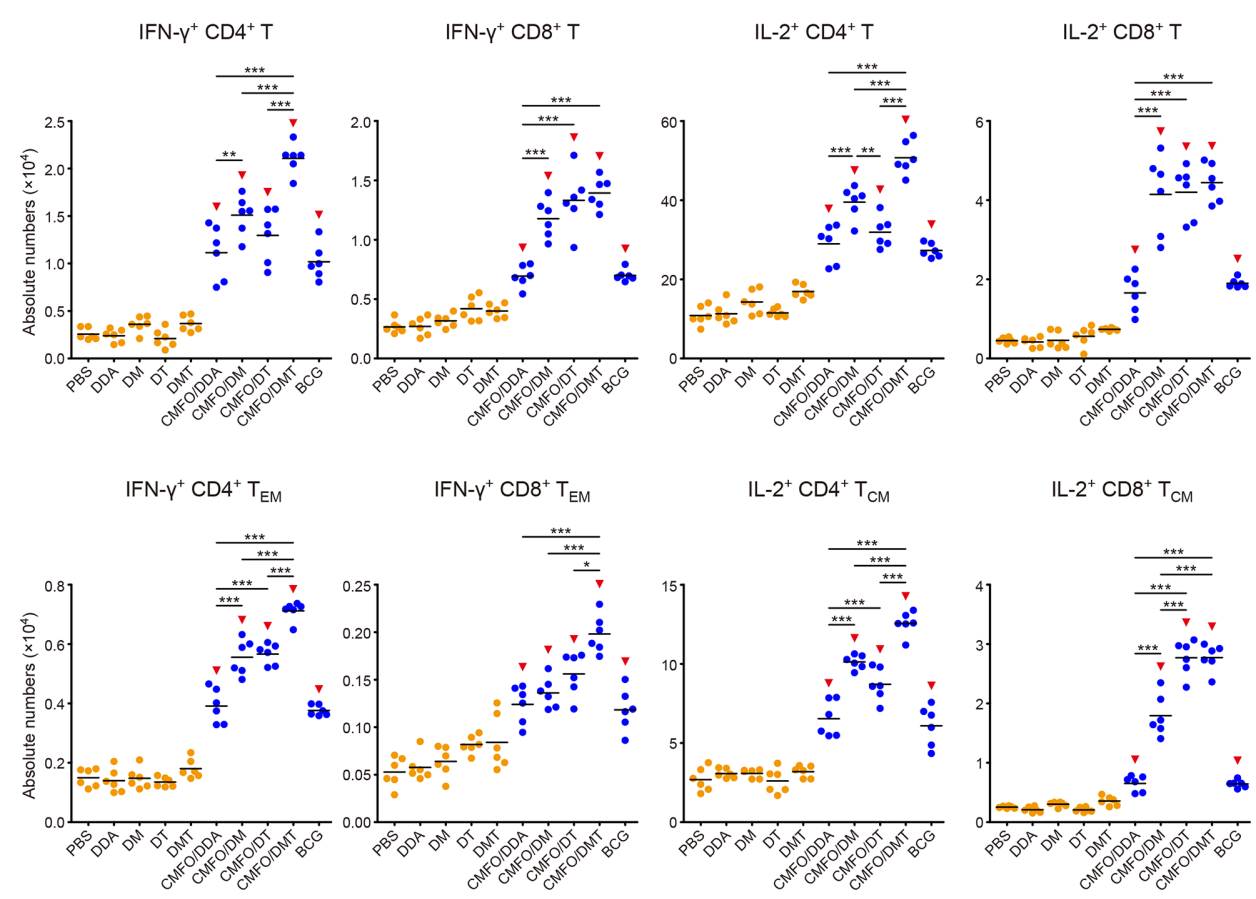

FIGURE 10 | Comparison of the levels of CMFO-specific T cells in the lung of different immunized mice after exposure ( $\mathrm{n}=6$ ). Nine weeks after immunization, C57BL/6 mice were challenged with $M$. tuberculosis. Four weeks after infection, the absolute numbers of CMFO-specific IFN- $\gamma^{+}$CD4 ${ }^{+}$(or CD8 ${ }^{+}$) T cells, IFN- $\gamma^{+}$CD4 ${ }^{+}$ (or CD8 ${ }^{+}$) $\mathrm{T}_{\mathrm{EM}}$ cells, IL-2 $2^{+} \mathrm{CD} 4^{+}$(or CD8 ${ }^{+}$) T cells, and IL-2 ${ }^{+} \mathrm{CD} 4^{+}$(or CD8 ${ }^{+}$) $\mathrm{T}_{\mathrm{CM}}$ cells per lung were detected. All experiments were repeated twice and similar results were obtained. The line in each group represented mean value. ${ }^{\star} p<0.05,{ }^{* \star} p<0.01,{ }^{\star \star *} p<0.001$, and ${ }^{\nabla} p<0.05$ vs. respective controls. Representative FACS plots were shown in Figure S4.

MPLA and TDB via binding to TLR4 and Mincle (Figure 11). Most importantly, higher levels of effector and central memory $\mathrm{T}$ cells correspond to the better vaccine-induced protection against TB as demonstrated in previous studies $(7,17,53)$. Differential $\mathrm{T}$ cell responses in the spleen and lung before and after exposure were also induced by different subunit vaccines in this study. $\mathrm{CD}^{+} \mathrm{T}$ cells play a central role in adaptive immune responses for TB control and even clearance. Vaccineinduced immunological memory is the key to provide lifelong protection. Memory $\mathrm{T}$ cells exist in at least two subpopulations, namely, $\mathrm{T}_{\mathrm{EM}}$ and $\mathrm{T}_{\mathrm{CM}}$ cells $(54,55) . \mathrm{T}_{\mathrm{EM}}$ cells express receptors needed for the migration into non-lymphoid organs, which immediately produce microbicidal lymphokines upon reactivation $(54,55) . \mathrm{T}_{\mathrm{CM}}$ cells express high levels of CCR7, which direct recirculation through lymph nodes and proliferate to produce new antigen-specific $\mathrm{CD} 4^{+} \mathrm{T}$ cells (54, 55). IL- $2^{+} \mathrm{CD} 4^{+} \mathrm{T}$ cells, especially IL-2 ${ }^{+} \mathrm{CD} 4^{+} \mathrm{T}_{\mathrm{CM}}$ cells might play a pivotal role in vaccine-induced protection as these cells were dominated in the lung of CMFO/DMT vaccinated mice after $M$. tuberculosis infection. In addition, the adjuvants DDA/MPLA and DDA/TDB could elicit different kinds of T cells in the spleen and lung. Depending on the mechanisms of the required protective immunity, these adjuvants can be utilized to develop subunit vaccines for preventing against different infectious diseases.
Taken together, our findings have illustrated a synergistic effect among subcomponents MPLA and TDB of the adjuvant DMT, which together contribute an enhanced immunogenicity and better longer-lasting protection of the CMFO/DMT vaccine against primary progressive TB. Therefore, the current work is an important extension of the CMFO/DMT vaccine. Given a crucial role of adjuvants in vaccine-induced protection, a combinational strategy with different PRR agonists might be a direction deserved for further investigation toward a nextgeneration $\mathrm{TB}$ vaccine.

\section{DATA AVAILABILITY STATEMENT}

The raw data supporting the conclusions of this article will be made available by the authors, without undue reservation.

\section{ETHICS STATEMENT}

The animal study was reviewed and approved by the Committee on the Ethics of Animal Experiments and the School Committee on Biosafety of Tongji Medical College, Huazhong University of Science and Technology. 

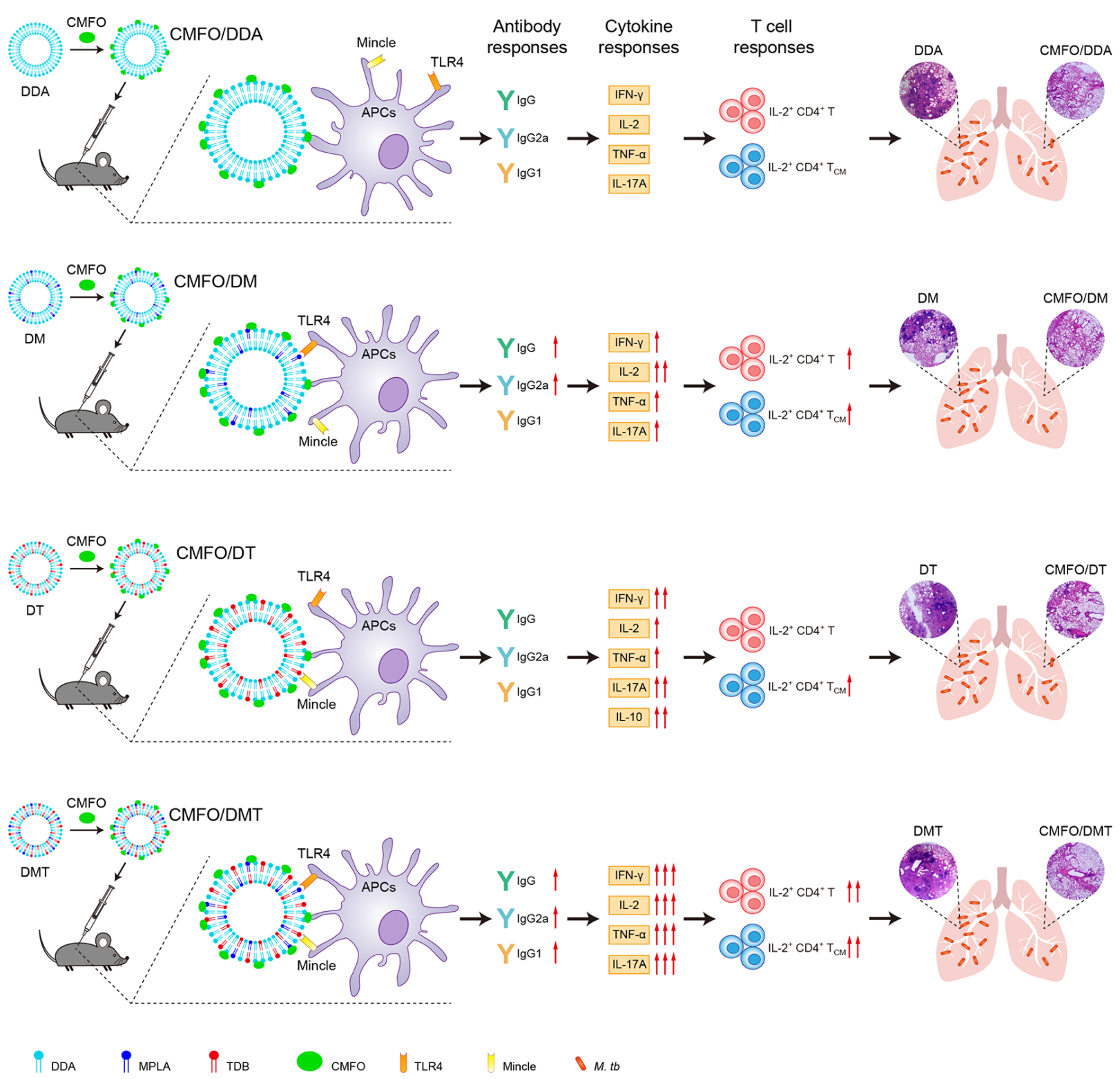

FIGURE 11 | Overview of the mechanism of different liposomal adjuvanted CMFO subunit vaccines.

\section{AUTHOR CONTRIBUTIONS}

This project was designed by XF. LH, YW, ZZ, QL, YZ, NU, J-LBN, and XL performed the experiments. LH, XF, YW, ZZ, and QL analyzed the data. LH wrote the manuscript and the final manuscript was revised thoroughly by XF.

\section{FUNDING}

This work was supported by grants from the National MegaProjects of Science Research for the 13th Five-year Plan of China
(No. 2018ZX10302302002-001), the Natural Science Foundation of China (No. 81772147, 81971909), the Fundamental Research Funds for the Central Universities (HUST COVID-19 Rapid Response Call No. 2020kfyXGYJ040), and the R\&D program of Wuhan Bureau of Science and Technology (No. 2020020601012218).

\section{SUPPLEMENTARY MATERIAL}

The Supplementary Material for this article can be found online at: https://www.frontiersin.org/articles/10.3389/fimmu.2020. 575504/full\#supplementary-material 


\section{REFERENCES}

1. Mangtani P, Abubakar I, Ariti C, Beynon R, Pimpin L, Fine PE, et al. Protection by BCG vaccine against tuberculosis: a systematic review of randomized controlled trials. Clin Infect Dis (2014) 58(4):470-80. doi: $10.1093 / \mathrm{cid} / \mathrm{cit} 790$

2. WHO. Global Tuberculosis Report 2019. Geneva, Switzerland: United Nations, World Health Organization (WHO (2019). Available at: http://www.who.int/ tb/publications/global_report/en/.

3. WHO. Latent TB infection: updated and consolidated guidelines for programmatic management. Geneva: World Health Organization (2018).

4. Andersen P, Scriba TJ. Moving tuberculosis vaccines from theory to practice. Nat Rev Immunol (2019) 19(9):550-62. doi: 10.1038/s41577-019-0174-Z

5. Wang X, Zhang J, Liang J, Zhang Y, Teng X, Yuan X, et al. Protection against Mycobacterium tuberculosis infection offered by a new multistage subunit vaccine correlates with increased number of IFN- $\gamma+$ IL- $2+$ CD4+ and IFN- $\gamma+$ CD8+ T cells. PLoS One (2015) 10(3):e0122560. doi: 10.1371/journal.pone.0122560

6. Yu Q, Wang X, Fan X. A New Adjuvant MTOM Mediates Mycobacterium tuberculosis Subunit Vaccine to Enhance Th1-Type T Cell Immune Responses and IL-2 ${ }^{+}$T Cells. Front Immunol (2017) 8:585. doi: 10.3389/ fimmu.2017.00585

7. Ma J, Teng X, Wang X, Fan X, Wu Y, Tian M, et al. A Multistage Subunit Vaccine Effectively Protects Mice Against Primary Progressive Tuberculosis, Latency and Reactivation. EBioMedicine (2017) 22:143-54. doi: 10.1016/ j.ebiom.2017.07.005

8. Bertholet S, Ireton GC, Ordway DJ, Windish HP, Pine SO, Kahn M, et al. A defined tuberculosis vaccine candidate boosts BCG and protects against multidrug-resistant Mycobacterium tuberculosis. Sci Transl Med (2010) 2 (53):53ra74. doi: 10.1126/scitranslmed.3001094

9. Aagaard C, Hoang T, Dietrich J, Cardona PJ, Izzo A, Dolganov G, et al. A multistage tuberculosis vaccine that confers efficient protection before and after exposure. Nat Med (2011) 17(2):189-94. doi: 10.1038/nm.2285

10. Darrah PA, DiFazio RM, Maiello P, Gideon HP, Myers AJ, Rodgers MA, et al. Boosting BCG with proteins or rAd5 does not enhance protection against tuberculosis in rhesus macaques. NPJ Vaccines (2019) 4:21. doi: 10.1038/ s41541-019-0113-9

11. Tait DR, Hatherill M, Van Der Meeren O, Ginsberg AM, Van Brakel E, Salaun B, et al. Final Analysis of a Trial of M72/AS01E Vaccine to Prevent Tuberculosis. N Engl J Med (2019) 381(25):2429-39. doi: 10.1056/ NEJMoa1909953

12. Nemes E, Geldenhuys H, Rozot V, Rutkowski KT, Ratangee F, Bilek N, et al. Prevention of M. tuberculosis Infection with H4:IC31 Vaccine or BCG Revaccination. N Engl J Med (2018) 379(2):138-49. doi: 10.1056/ NEJMoa1714021

13. Harris RC, Dodd PJ, White RG. The potential impact of BCG vaccine supply shortages on global paediatric tuberculosis mortality. BMC Med (2016) 14 (1):138. doi: 10.1186/s12916-016-0685-4

14. Mata-Haro V, Cekic C, Martin M, Chilton PM, Casella CR, Mitchell TC. The vaccine adjuvant monophosphoryl lipid A as a TRIF-biased agonist of TLR4. Science (2007) 316(5831):1628-32. doi: 10.1126/science.1138963

15. Schoenen H, Bodendorfer B, Hitchens K, Manzanero S, Werninghaus K, Nimmerjahn $\mathrm{F}$, et al. Cutting edge: mincle is essential for recognition and adjuvanticity of the mycobacterial cord factor and its synthetic analog trehalose-dibehenate. I Immunol (2010) 184(6):2756-60. doi: 10.4049/ jimmunol.0904013

16. Teng X, Tian M, Li J, Tan S, Yuan X, Yu Q, et al. Immunogenicity and protective efficacy of DMT liposome-adjuvanted tuberculosis subunit CTT3H vaccine. Hum Vaccin Immunother (2015) 11(6):1456-64. doi: 10.1080/ 21645515.2015.1037057

17. van Dissel JT, Joosten SA, Hoff ST, Soonawala D, Prins C, Hokey DA, et al. A novel liposomal adjuvant system, CAF01, promotes long-lived Mycobacterium tuberculosis-specific T-cell responses in human. Vaccine (2014) 32(52):7098-107. doi: 10.1016/j.vaccine.2014.10.036

18. Kolanowski ST, Dieker MC, Lissenberg-Thunnissen SN, van Schijndel GM, van Ham SM, ten Brinke A. TLR4-mediated pro-inflammatory dendritic cell differentiation in humans requires the combined action of MyD88 and TRIF. Innate Immun (2014) 20(4):423-30. doi: 10.1177/1753425913498626
19. Dendouga N, Fochesato M, Lockman L, Mossman S, Giannini SL. Cellmediated immune responses to a varicella-zoster virus glycoprotein $\mathrm{E}$ vaccine using both a TLR agonist and QS21 in mice. Vaccine (2012) 30(20):3126-35. doi: 10.1016/j.vaccine.2012.01.088

20. Casella CR, Mitchell TC. Putting endotoxin to work for us: monophosphoryl lipid A as a safe and effective vaccine adjuvant. Cell Mol Life Sci (2008) 65 (20):3231-40. doi: 10.1007/s00018-008-8228-6

21. Ishikawa E, Ishikawa T, Morita YS, Toyonaga K, Yamada H, Takeuchi O, et al. Direct recognition of the mycobacterial glycolipid, trehalose dimycolate, by Ctype lectin Mincle. J Exp Med (2009) 206(13):2879-88. doi: 10.1084/ jem.20091750

22. Desel C, Werninghaus K, Ritter M, Jozefowski K, Wenzel J, Russkamp N, et al. The Mincle-activating adjuvant TDB induces MyD88-dependent Th1 and Th17 responses through IL-1R signaling. PLoS One (2013) 8(1):e53531. doi: 10.1371/journal.pone.0053531

23. Werninghaus K, Babiak A, Gross O, Hölscher C, Dietrich H, Agger EM, et al. Adjuvanticity of a synthetic cord factor analogue for subunit Mycobacterium tuberculosis vaccination requires FcRgamma-Syk-Card9-dependent innate immune activation. J Exp Med (2009) 206(1):89-97. doi: 10.1084/ jem.20081445

24. Idoko OT, Owolabi OA, Owiafe PK, Moris P, Odutola A, Bollaerts A, et al. Safety and immunogenicity of the M72/AS01 candidate tuberculosis vaccine when given as a booster to BCG in Gambian infants: an open-label randomized controlled trial. Tuberculosis (Edinb) (2014) 94(6):564-78. doi: 10.1016/j.tube.2014.07.001

25. Tian M, Zhou Z, Tan S, Fan X, Li L, Ullah N. Formulation in DDA-MPLATDB Liposome Enhances the Immunogenicity and Protective Efficacy of a DNA Vaccine against Mycobacterium tuberculosis Infection. Front Immunol (2018) 9:310. doi: 10.3389/fimmu.2018.00310

26. Nordly P, Agger EM, Andersen P, Nielsen HM, Foged C. Incorporation of the TLR4 agonist monophosphoryl lipid A into the bilayer of DDA/TDB liposomes: physico-chemical characterization and induction of CD8+ T-cell responses in vivo. Pharm Res (2011) 28(3):553-62. doi: 10.1007/s11095-0100301-9

27. Brennan MJ, Clagett B, Fitzgerald H, Chen V, Williams A, Izzo AA, et al. Preclinical evidence for implementing a prime-boost vaccine strategy for tuberculosis. Vaccine (2012) 30:2811-23. doi: 10.1016/j.vaccine.2012. 02.036

28. Nieuwenhuizen NE, Kaufmann SHE. Next-generation vaccines based on Bacille Calmette-Guerin. Front Immunol (2018) 9:121. doi: 10.3389/ fimmu.2018.00121

29. Schellack C, Prinz K, Egyed A, Fritz JH, Wittmann B, Ginzler M, et al. IC31, a novel adjuvant signaling via TLR9, induces potent cellular and humoral immune responses. Vaccine (2006) 24(26):5461-72. doi: 10.1016/ j.vaccine.2006.03.071

30. Henriksen-Lacey M, Christensen D, Bramwell VW, Lindenstrøm T, Agger EM, Andersen P, et al. Liposomal cationic charge and antigen adsorption are important properties for the efficient deposition of antigen at the injection site and ability of the vaccine to induce a CMI response. J Control Release (2010) 145(2):102-8. doi: 10.1016/j.jconrel.2010.03.027

31. Henriksen-Lacey M, Bramwell VW, Christensen D, Agger EM, Andersen P, Perrie Y. Liposomes based on dimethyldioctadecylammonium promote a depot effect and enhance immunogenicity of soluble antigen. J Control Release (2010) 142(2):180-6. doi: 10.1016/j.jconrel.2009.10.022

32. Ciurana CL, Zwart B, van Mierlo G, Hack CE. Complement activation by necrotic cells in normal plasma environment compares to that by late apoptotic cells and involves predominantly IgM. Eur J Immunol (2004) 34 (9):2609-19. doi: 10.1002/eji.200425045

33. Williams A, Reljic R, Naylor I, Clark SO, Falero-Diaz G, Singh M, et al. Passive protection with immunoglobulin A antibodies against tuberculous early infection of the lungs. Immunology (2004) 111(3):328-33. doi: 10.1111/ j.1365-2567.2004.01809.x

34. Guirado E, Amat I, Gil O, Díaz J, Arcos V, Caceres N, et al. Passive serum therapy with polyclonal antibodies against Mycobacterium tuberculosis protects against post-chemotherapy relapse of tuberculosis infection in SCID mice. Microbes Infect (2006) 8(5):1252-9. doi: 10.1016/ j.micinf.2005.12.004 
35. Huygen K, Content J, Denis O, Montgomery DL, Yawman AM, Deck RR, et al. Immunogenicity and protective efficacy of a tuberculosis DNA vaccine. Nat Med (1996) 2(8):893-8. doi: 10.1038/nm0896-893

36. Achkar JM, Casadevall A. Antibody-mediated immunity against tuberculosis: implications for vaccine development. Cell Host Microbe (2013) 13(3):250-62. doi: 10.1016/j.chom.2013.02.009

37. Logan E, Luabeya AKK, Mulenga H, Mrdjen D, Ontong C, Cunningham AF, et al. Elevated IgG Responses in Infants Are Associated With Reduced Prevalence of Mycobacterium tuberculosis Infection. Front Immunol (2018) 9:1529. doi: 10.3389/fimmu.2018.01529

38. Donald PR, Marais BJ, Barry CE3. Age and the epidemiology and pathogenesis of tuberculosis. Lancet (2010) 375(9729):1852-4. doi: 10.1016/ S0140-6736(10)60580-6

39. Maglione PJ, Xu J, Chan J. B cells moderate inflammatory progression and enhance bacterial containment upon pulmonary challenge with Mycobacterium tuberculosis. J Immunol (2007) 178(11):7222-34. doi: 10.4049/jimmunol.178.11.7222

40. Agger EM, Cassidy JP, Brady J, Korsholm KS, Vingsbo-Lundberg C, Andersen P. Adjuvant modulation of the cytokine balance in Mycobacterium tuberculosis subunit vaccines; immunity, pathology and protection. Immunology (2008) 124(2):175-85. doi: 10.1111/j.1365-2567.2007.02751.x

41. Redford PS, Murray PJ, O'Garra A. The role of IL-10 in immune regulation during M. tuberculosis infection. Mucosal Immunol (2011) 4(3):261-70. doi: $10.1038 / \mathrm{mi} .2011 .7$

42. Gesser B, Leffers H, Jinquan T, Vestergaard C, Kirstein N, Sindet-Pedersen S, et al. Identification of functional domains on human interleukin 10. Proc Natl Acad Sci U S A (1997) 94(26):14620-5. doi: 10.1073/pnas.94.26.14620

43. Flynn JL, Chan J, Lin PL. Macrophages and control of granulomatous inflammation in tuberculosis. Mucosal Immunol (2011) 4(3):271-8. doi: $10.1038 / \mathrm{mi} .2011 .14$

44. Weiss G, Schaible UE. Macrophage defense mechanisms against intracellular bacteria. Immunol Rev (2015) 264(1):182-203. doi: 10.1111/imr.12266

45. Cooper AM, Dalton DK, Stewart TA, Griffin JP, Russell DG, Orme IM. Disseminated tuberculosis in interferon gamma gene-disrupted mice. J Exp Med (1993) 178(6):2243-7. doi: 10.1084/jem.178.6.2243

46. Harris J, Keane J. How tumour necrosis factor blockers interfere with tuberculosis immunity. Clin Exp Immunol (2010) 161(1):1-9. doi: 10.1111/ j.1365-2249.2010.04146.x

47. Roach DR, Bean AG, Demangel C, France MP, Briscoe H, Britton WJ. TNF regulates chemokine induction essential for cell recruitment, granuloma formation, and clearance of mycobacterial infection. J Immunol (2002) 168 (9):4620-7. doi: 10.4049/jimmunol.168.9.4620
48. Kelso A, MacDonald HR, Smith KA, Cerottini JC, Brunner KT. Interleukin 2 enhancement of lymphokine secretion by $\mathrm{T}$ lymphocytes: analysis of established clones and primary limiting dilution microcultures. J Immunol (1984) 132(6):2932-8. doi: 10.1002/cber.19190520306

49. Yoshida YO, Umemura M, Yahagi A, O’Brien RL, Ikuta K, Kishihara K, et al. Essential role of IL-17A in the formation of a mycobacterial infection-induced granuloma in the lung. J Immunol (2010) 184(8):4414-22. doi: 10.4049/ jimmunol.0903332

50. Umemura M, Yahagi A, Hamada S, Begum MD, Watanabe H, Kawakami K, et al. IL-17-mediated regulation of innate and acquired immune response against pulmonary Mycobacterium bovis bacille Calmette-Guerin infection. J Immunol (2007) 178(6):3786-96. doi: 10.4049/jimmunol.178.6.3786

51. Fogli LK, Sundrud MS, Goel S, Bajwa S, Jensen K, Derudder E, et al. T cellderived IL-17 mediates epithelial changes in the airway and drives pulmonary neutrophilia. J Immunol (2013) 191(6):3100-11. doi: 10.4049/ jimmunol.1301360

52. Saunders BM, Frank AA, Orme IM, Cooper AM. Interleukin-6 induces early gamma interferon production in the infected lung but is not required for generation of specific immunity to Mycobacterium tuberculosis infection. Infect Immun (2000) 68(6):3322-6. doi: 10.1128/IAI.68.6.3322-3326.2000

53. Ma J, Tian M, Fan X, Yu Q, Jing Y, Wang W, et al. Mycobacterium tuberculosis multistage antigens confer comprehensive protection against pre- and post-exposure infections by driving Th1-type $\mathrm{T}$ cell immunity. Oncotarget (2016) 7(39):63804-15. doi: 10.18632/oncotarget.11542

54. Sallusto F, Geginat J, Lanzavecchia A. Central memory and effector memory T cell subsets: function, generation, and maintenance. Annu Rev Immunol (2004) 22:745-63. doi: 10.1146/annurev.immunol.22.012703.104702

55. Reinhardt RL, Khoruts A, Merica R, Zell T, Jenkins MK. Visualizing the generation of memory CD4 T cells in the whole body. Nature (2001) 410 (6824):101-5. doi: 10.1038/35065111

Conflict of Interest: The authors declare that the research was conducted in the absence of any commercial or financial relationships that could be construed as a potential conflict of interest.

Copyright (c) $2020 \mathrm{Hao}, \mathrm{Wu}$, Zhang, Zhou, Lei, Ullah, Banga Ndzouboukou, Lin and Fan. This is an open-access article distributed under the terms of the Creative Commons Attribution License (CC BY). The use, distribution or reproduction in other forums is permitted, provided the original author(s) and the copyright owner(s) are credited and that the original publication in this journal is cited, in accordance with accepted academic practice. No use, distribution or reproduction is permitted which does not comply with these terms. 